\title{
Special Issue in Honor of Dr. Elias K. Michaelis
}

\author{
In-Young Choi ${ }^{1}$. Arne Schousboe ${ }^{2}$
}

Received: 12 December 2018 / Revised: 12 December 2018 / Accepted: 12 December 2018 / Published online: 2 January 2019

o) Springer Science+Business Media, LLC, part of Springer Nature 2018

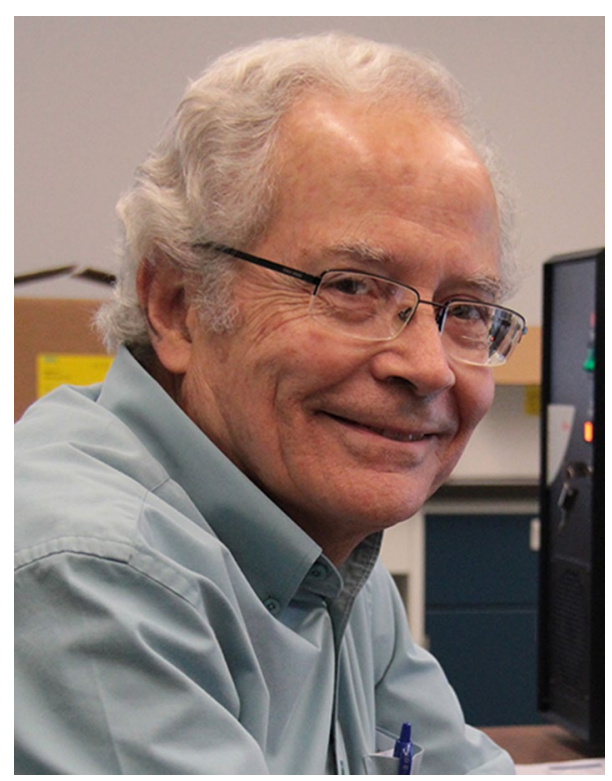

This first issue of 2019 has been assembled to honor Prof. Elias (Eli) Michaelis, in the tradition of special issues of Neurochemical Research dedicated in honor of outstanding neurochemists. This issue includes various topics that have been related to Eli's research areas: glutamate neurotransmission and metabolism, mitochondrial function, calcium regulation, oxidative stress in aging, alcoholism, and neurodegeneration.

It is difficult to find words that are superlative enough to describe Eli whose outstanding career in the areas of

Special issue in honor of Prof. Eli Michaelis.

In-Young Choi

ichoi@kumc.edu; iychoi0@gmail.com

1 University of Kansas Medical Center, 3901 Rainbow Blvd., Mail Stop 1052, Kanas City, KS, USA

2 University of Copenhagen, Copenhagen, Denmark leadership, teaching, research, and service have spanned a myriad of roles and research topics, and who enjoys high esteem among his colleagues. Eli truly exemplifies what it means to be a visionary, a leader, an academician, a professor, a scientist, and a mentor. Having devoted more than 45 years to science at the University of Kansas since 1973, Eli's steady and unflinching passion for science has led him to pursue a broad range of research areas in neurochemistry, cell and molecular neurobiology, pharmacology and toxicology.

$\mathrm{He}$ is the recipient of numerous prestigious awards, including a special fellowship by the National Institute on Neurological Diseases and Stroke that allowed him to transition from clinical medicine to experimental neurochemistry, a MERIT award from the National Institute on Alcoholism and Alcohol Abuse, the Higuchi Award for Biomedical Sciences at the University of Kansas, and a Distinguished Alumnus Award from St. Louis University School of Medicine. His commitment to service has led him 
to serve in many roles in the academic and scientific community, including as department chair and as director of a multidisciplinary research center at the University of Kansas. He has served on and chaired numerous scientific review committees at the National Institutes of Health, the Veterans Administration Merit Awards, and the Alzheimer's Disease Drug Discovery Foundation. In recognition of his scientific work the University of Kansas named him a University Distinguished Professor. Eli has maintained continuous funding for his research over a period of 45 years, including several multi-investigator research programs. This has allowed him to devote himself to training graduate students, postdoctoral fellows, and faculty with the aim of building a strong foundation for their careers and research goals, and many of them have gone on to successful careers as highly respected scientists.

Eli was born and raised in Sudan and almost followed in his father's footsteps as a physician. He entered the St. Louis University School of Medicine where he received his M.D. degree in 1969. After graduation and while serving in the United States Public Health Service in Kentucky, he initiated a research project at the University of Kentucky on the characterization of the molecular properties of glutamate receptors in the central nervous system. He received his Ph.D. in 1973 from the University of Kentucky School of Medicine in Physiology and Biophysics and he took a position as an Assistant Professor at the University of Kansas.

At a time when there were practically no chemical tools to activate or inhibit glutamate receptors, Eli and his students and post-docs published a series of studies on the extraction from plasma membranes, isolation, and reconstitution of proteins with glutamate-binding characteristics expected of receptors. He and his colleagues continued these efforts over the years leading to the development of immunochemical tools that led to the cloning of the cDNA's of four proteins forming a complex with the binding sites and ion conductance similar to those of NMDA glutamate receptors, Together with his wife, Mary Michaelis, he also worked on biochemical measurements of calcium regulating enzyme (ATPase) and transport carrier (sodium-calcium exchanger) activities in isolated synaptic plasma membrane preparations as calcium fluxes play such a crucial role in glutamate receptor signaling. Mary Michaelis has continued and greatly expanded this line of neurochemical research in calcium regulation.

Glutamate neurotransmission was the very first topic that drew Eli to neurochemical investigations and inspired his tireless efforts to understand the biochemical events associated with glutamate signaling and the effects of alcohol intake, oxidative stress, and aging on this signaling in the central nervous system. To probe further the regulation of glutamate activity in the brain, Eli and his colleagues in more recent years, focused on glutamate metabolism and the role of the enzyme glutamate dehydrogenase on synaptic glutamate activity. Having generated transgenic mice that overexpress this enzyme in brain neurons only, Eli has shown the importance of this enzyme in maintaining the levels of releasable glutamate in neurons, and the effects that it has on synaptic transmission, neuronal synapse structure, and neuronal survival during aging, In addition, Eli and his colleagues have explored the gene expression patterns most affected by the overexpression of glutamate dehydrogenase and the changes in such patterns throughout the lifespan. As is apparent, starting from the point of trying to understand how glutamate may function in the brain at the molecular level, Eli has made substantial contributions to neurochemistry across a range of research areas, including his notable and pioneering work on the effects of alcoholism on glutamate neurotransmission, as well as the effects of altered glutamate metabolism in increased resistance to brain ischemia. His transgenic mouse model with an excess generation of glutamate in neurons has contributed to our understanding of the role of glutamate in the aging brain and led him to the study of Alzheimer's disease as he extended his focus to mitochondrial metabolism and genetic and genomic studies of mitochondrial DNA.

Throughout his career, Eli maintained close professional and personal relationships with many scientists around the world and was appreciated by many of us for his warm personality and quick wit, as well as his many contributions to neuroscience as a researcher, as a colleague, and as a friend. Dr. Asma Zaidi has expressed that she counts herself lucky for having his guidance and mentorship to fuel her passion for science and discovery and pushed her to greater heights in her work. I myself have been extremely fortunate that he was the first neuroscientist I worked with when I joined the faculty of the University of Kansas Medical Center in 2005.

Many have expressed that this dedicated issue was both timely and well-deserved. The many heartfelt messages about Eli that we received when we inquired of potential contributors to this issue are a testament to his lasting influence and the strength of his contributions to the field, and you may review some of these for yourself below.

Both Eli and Mary Lou Michaelis were teachers in a graduate-level course in pharmacology that I took during my doctoral studies in medicinal chemistry at the University of Kansas, and I fondly remember their lectures as being well organized, informative, and interesting. Little did I suspect that I would cross paths with them some 15 years later in an entirely different context. As an independent investigator, I began working on Alzheimer's disease, and I was pleasantly surprised to see them at a conference run by the Alzheimer Drug Discovery Foundation held in New York City. We met more or less regularly at this conference after that, and I always enjoyed catching up with them personally and hearing their passion for working to solve the difficult problem of 
neurodegenerative diseases. In October of 2016, I returned to the University of Kansas to continue my work in this area, and I am extremely gratified to now have the Drs. Michaelis as my colleagues. I consider it a great privilege to be invited to contribute my latest thoughts on the molecular basis of Alzheimer's disease in this special issue in honor of Prof. Eli Michaelis (from Michael Scott Wolfe, Ph.D.).

About 10 years ago, Elias attended the First International Meeting on Glutamate Dehydrogenase that we had organized on Crete. By then, we knew of his important work on glutamate receptors and on the glutamatergic system in general. We also knew his pioneer work on the genetic and other factors that render selected brain regions and nerve cells vulnerable to metabolic insults, including ethanol intoxication, oxidative stress and glutamate excitotoxicity, as well as to the aging process. His group had created an excellent transgenic mouse overexpressing mouse glutamate dehydrogenase in neurons, a long-sought model for the study of aberrant glutamate metabolism. Their seminal 2009 paper in J Neuroscience, showing the effect of excess synaptic glutamate on age-associated neurodegenerative processes, was a real breakthrough for us all working in the field. Elias presentation on Crete verified his legacy as an excellent scientist and a source of inspiration for young neuroscientists. Indeed, during the Crete symposium he met and interacted with our graduate students and post-doctoral fellows, providing them with valuable insights and on how to further advance their carrier. Elias has a nice personality, easily fostering friendships. We have very fond memories of Elias and we consider ourselves lucky that we got to know him (from Andreas Plaitakis, M.D., Ph.D. and Ioannis Zaganas, M.D., Ph.D.).

The remarkable scientific contributions of Dr. Elias Michaelis and the chance to have met him at an RSA congress in 1999 prompted me to apply for a postdoctoral fellowship in his research laboratory. Dr. Michaelis was for me a fantastic mentor who instilled in me the scientific rigor and the desire to push his limits. I was struck by the human qualities of Dr. Michaelis and his way of creating the link between the researchers of his team to ultimately develop a strong sense of belonging and allow us to be proud to work with him. I learned a lot from him not only in terms of scientific knowledge about the role of glutamate and its receptors in the effects of alcohol but also humanly. I was impressed at the time by the quality of his work and the discovery of new proteins forming a complex with the properties of an ion channel with the characteristics of a glutamate receptor like the NMDA receptor. In addition, like the proteins of the NMDA receptor, the identified proteins were also regulated by exposure to ethanol. Dr. Michaelis used to discuss very regularly with all the members of his group, to come and talk on the bench and to give even technical advice. At the end of this postdoctoral internship, the research experience in Dr. Michaelis' laboratory convinced me to continue in the same direction and to create in France the first research laboratory completely dedicated to alcohol addiction. I owe him so much and I take this opportunity to thank him deeply and to show him my greatest respect (from Mickael Naassila, Ph.D.).

Dr. Michaelis started his career as a medical doctor with a goal to improve people's health and to save lives. Following his instinct, he chose a life-long research career to achieve the goal. Over the years, he has made outstanding contributions to the fields of aging and neurodegeneration and continues doing so. For example, he reported isolation and characterization of cDNA for the glutamate-binding subunit of an NMDA receptor complex in Nature in 1991. Another outstanding contribution of Dr. Michaelis to the scientific research community is his lifetime dedication to training young scientists. Among the careers of his students are professors at Universities, leaders of laboratories at research institutions, and experts in in the pharmaceutical or biotechnology industry. Furthermore, his outstanding leadership and excellence in mentoring have shaped the career of many junior faculty members at the University of Kansas. When asked recently how younger scientists deal with the current harsh funding environment, he advised based on his own experience that "Faith. Faith will help overcome difficult times" (from Honglian Shi, Ph.D.).

A unique character of Dr. Elias K. Michaelis is that you never get bored when having a science-talk with him. I remember my interview with him for a senior postdoctoral position in his lab in July 1997. We had a straight 3-h conversation about glutamate biology, NMDA receptors and aging. Staying on the top of his field, encouraging his team members to tryi new methods and approaches in our studies, and sometimes working in the wet lab, showing us, for example, how to dissect out the hippocampus from rat brain; that partially describes my mentor Dr. Elias K. Michaelis. His major contribution to neuroscience was to discover the brain synaptic membrane glutamate binding protein I worked with him in his three-times renewed 5 year continuously funded NIH-program project. I have learned a great deal of how to review grants at my early stage of academic career. Dr. Michaelis is not only a physician-scientist but also an effective critic. When the data presented to him in our regular lab meetings he would start with praise for the work done and time spent; then after that, he went into details and made challenges in a way that nobody in the room felt uncomfortable. I am using the same technique in my lab and my research team (Team- $Q$ ) feels that they are valued for their contribution as I felt in Dr. Michaelis' lab two decades ago (from A. Baki Agbas, M.Sc., Ph.D.).

Dr. Elias Michaelis was devoted to a wide variety of research in areas of neurological disease, such as alcohol abuse and related brain damage, stroke, seizure neurobiology, and age-associated neurodegeneration. Glutamate neurotransmission is the most extensive excitatory neurotransmitter in the 
brain and spinal cord, and a key factor involved in neuronal excitability and neuronal death. His distinguished achievements have been due to his unceasing efforts with frontier spirit preparing for tomorrow. Over the past 50 years, his scientific contributions on the glutamate system have been the main activity in the field. My individual experience with him is very short, but I can discern his trust and respect for scientific researchers in the field, including me, and that he wants to help those who follow him accomplish more creative works (from Eun Joo Baik, Ph.D.).

We at Neurochemical Research want to express our extreme gratitude to all its contributing authors. We are also grateful to be able to present this special issue in Eli's honor, and it goes without saying that all of us have a deep respect for Eli's body of work and hold him in the highest esteem. We hope to see him continue to inspire neurochemists and neuroscientists, both in the present and for years to come.

In-Young Choi, Ph.D. and Arne Schousboe, D.Sc. Guest Editors

Publisher's Note Springer Nature remains neutral with regard to jurisdictional claims in published maps and institutional affiliations. 